\title{
Local Brand Marketing Concept Communication Strategy under the New Media Environment
}

\author{
Yiying Wang \\ Department of Radio and Television, College of literature , BaiCheng Normal University, Baicheng ,China. \\ yiying0626@163.com
}

Keywords: New media environment; Local brands; Marketing philosophy; Communication strategy

\begin{abstract}
Traditional communication strategies cannot adapt effectively to the new media environment, and the brand communication effect is poor. In this way, a design of local brand marketing concept communication strategy under the new media environment is carry out. The design of local brand marketing concept communication strategy under the new media environment is divided into three parts: By creating a differentiated brand positioning and meeting differentiated audience needs, the differentiation strategy design of brand marketing concept communication can be realized. Through content integration, channel integration and mode integration, the integrated strategy design of brand marketing concept communication can be realized. The interactive strategy design of brand marketing concept communication is realized through two means of strengthening consumer experience and collecting consumer feedback. Complete the design of local brand marketing concept communication strategy under the new media environment. The validity of the design method is demonstrated experimentally. Experimental data show that the designed method can effectively adapt the communication strategy of local brand marketing concept to the new media environment, and the brand communication effect is better. Compared with the traditional method, the new media communication effect is improved by $28.16 \%$, and the brand communication effect is improved by $52 \%$.
\end{abstract}

\section{Introduction}

With the development of network technology and digital communication technology, many new media, represented by the Internet, have entered the field of communication one after another. The emergence of new media has changed people's work and life style, and changed the way, concept and effect of enterprise marketing. The analysis of brand connotation from different perspectives shows that under the premise of ensuring that the quality and function of products can satisfy consumers, enterprises also give additional information such as product name, color, reputation, service, culture, value, identity and status, etc. The additional information must be effectively communicated to target consumers, After a period of understanding, feeling and use, consumers form their feelings and impressions of the product and their attitudes and actions such as identification, trust and loyalty to the product and its additional information. Only then can the product become a "brand" ${ }^{[1]}$. The enterprise is the owner and operator of the brand, and the feeling, evaluation and recognition of the "brand" lies in the consumers. It is "communication" that links the two organically. The meaning of brand is transformed by communication, and "brand" is the product of "communication".

The current media and marketing approaches present a new pattern of diversification and integration. The allure of mass media such as newspapers, magazines, television and radio remains. The birth of new media such as BBS, BLDG and video gives brand more promotion methods. Marketing approaches such as advertising, promotion, public relations, packaging, sponsorship, etc. are constantly innovated and integrated in the process of brand creation and maintenance. The effect of brand communication is closely related to the choice and design of communication methods. Meanwhile, the brand pursues not only the optimization of short-term communication effect, but 
also the long-term brand effect. Therefore, brand communication is a series of interactive communication activities about brand information between brand owners and target audiences. If the communication method is not selected properly and the design is not reasonable, if the brand communication goal cannot be adjusted in time according to the market changes, the good communication effect cannot be achieved, and the brand is difficult to maintain vitality ${ }^{[2]}$. This decides that the enterprise's brand communication is a systematic, open and long-term project, which must put the selection and design of communication mode in an important position and make a good strategic planning of brand communication. The basic procedure is: review the main body of brand communication, understand and study the target audience, conduct brand market positioning, establish brand characterization, attach brand culture, determine brand communication information, select and combine communication media, implement integrated communication, measure brand communication effect and value assessment, control and adjustment of brand communication. This program constitutes a systematic project of brand communication, which makes the brand more dynamic and stronger and longevity in the systematic communication and update.Aiming at the above problems, this paper designs the communication strategy of local brand marketing idea under the new media environment

\section{Design of communication strategy of local brand marketing idea under new media environment}

In the context of new media, challenges and opportunities coexist in the communication of brand marketing concepts in China. Facing the current complex and changeful market environment, how to in the fierce market competition, enterprise brand information rapidly and accurately convey to the audience wants to convey, and harvested in the audience brand awareness, reputation and loyalty of good communication effect, need careful planning and effective implementation of the new media brand communication strategy ${ }^{[3]}$. The communication strategy design in this paper is divided into three parts, as shown in figure 1.

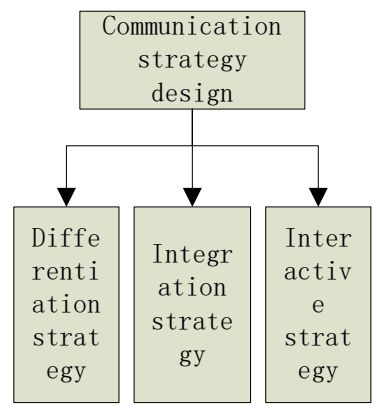

Figure 1. Division of brand marketing concept communication strategy design

\subsection{The differentiation strategy design of brand marketing concept communication}

By creating a differentiated brand positioning and meeting differentiated audience needs, the differentiation strategy design of brand marketing concept communication can be realized. To implement the differentiation strategy of brand communication, enterprises need to solve two problems: First, a differentiated brand positioning should be established. Brand positioning refers to the process of effectively establishing the difference between the brand of the enterprise and the brand of competitors, shaping a different image in the mind of consumers and then occupying a different position. Second, it should meet the needs of differentiated audiences. As can be seen from the successful experience of many top brands, only brands that truly understand the needs of consumers can finally gain the recognition of consumers ${ }^{[4]}$. In the context of new media, the brand's audience becomes more and more segmented and more selective. Only those enterprises that meet the needs of the differentiated audience can cope with the highly segmented market.

Brand positioning refers to the commercial decision of a specific brand on cultural orientation and personality differences on the basis of market positioning and product positioning. It is the process and result of building a brand image related to the target market. The differentiation 
performance of brand positioning is generally shown in the following formula:

$$
B=s+d+t(1)
$$

In the formula, $s$ means that the service philosophy is differentiated. The service concept expresses the business values of the enterprise and aims to make the products and services reach a high degree of agreement with the target audience. The service concept difference mentioned here mainly includes the difference of product type and operation mode. The type difference is what kind of goods are produced. Differences in service concepts include differences in the types of products produced, as well as differences in the modes of operation, such as exclusive stores, direct online sales, and combined online and offline sales ${ }^{[5]}$.

$d$ indicates design style differentiation. Distinctive differences in product design styles best reflect the differences in brand positioning of the product. Such as gothic style, British style, pastoral style, European and American style, Japanese and Korean style and traditional Chinese design style. If the product design style differentiation is significant enough, then the enterprise's brand positioning differentiation will be more obvious.

$t$ indicates the differentiation of target groups. The differences of target groups have been reflected from the differences of product types. The production of different types of products naturally targets at specific target groups with special demands for this type of products. The division of target groups is not only reflected in the age and gender factors, but also reflected in the occupation, status, consumption capacity and other factors, sometimes even reflected in the regional differences.

On the other hand, the needs of the audience are changing dynamically, and the value they pursue is constantly changing with the change of environment and conditions. The change of audience demand is always accompanied by economic development and scientific and technological progress. Economic development leads to the increase of people's income and provides internal impetus for the change of audience demand. And technological progress makes new products and new technologies constantly emerge, creating realistic conditions for audience demand changes. In recent years, in order to meet the needs of differentiated audiences, enterprises have made many explorations and attempts in database marketing, relationship marketing and brand micro content creation. Through the integration of customer data mastered by itself and the establishment of database, improve the ability of accurate analysis of audience demand; Maintain good relationship with customers through relationship marketing; Through the creation of brand micro content, to meet the differentiated audience needs ${ }^{[6]}$.

Through the above steps, the differentiation strategy design of brand marketing concept communication can be realized.

\subsection{The integrated strategy design of brand marketing concept communication}

Through content integration, channel integration and mode integration, the integrated strategy design of brand marketing concept communication can be realized.

Integrated marketing communication refers to reorganizing enterprise behavior and market behavior with consumers as the core. Use all forms of communication in an integrated and coordinated manner, with a unified goal and a unified communication image, delivering consistent product information, realize two-way communication with consumers, quickly establish the position of product brand in consumers' mind, establish a long-term close relationship between brand and consumers, achieve the purpose of advertising communication and product marketing more effectively $^{[7]}$. The implementation of integration strategy is mainly divided into three ways: content integration, channel integration and mode integration.

Content integration means that different media such as mobile phone, TV, network and magazine are regarded as integrated information terminals. To design and produce the communication content uniformly, instead of treating a single medium as an information terminal, independently carry out production of communication content. Content integration is the key to digital transformation of traditional media as well as an effective measure for brand communication under the background of new media. Enterprises can establish connections among different information terminals through 
content integration, which can not only make product information fully shared, but also reflect differences and realize complementary advantages.

With the development of new media, the boundaries between different media are not as clear and obvious as before. New and old media have their own place in the current media market, and continuously segment the media market, resulting in the confusion of channels and waste of resources. To sum up, only through integration among communication channels can the defects of individual media be remedied to form complementary advantages. Channel integration has brought more choice space and more flexibility for enterprises to carry out brand communication, and at the same time, it has also brought convenience for personalized marketing. Instead of relying solely on TV advertising for brand communication, enterprises can make personalized content at a lower cost, which is more conducive to building brand image ${ }^{[8]}$.

In today's new media era, the status of the mass media of traditional media has been broken, with diversified media types and absolutely efficient mass communication tools no longer available. Therefore, diversified brand communication means have become increasingly important. With the development and innovative application of new media, in addition to the commonly used methods of brand communication in the past, such as advertising, promotion, public relations and promotion, Chinese enterprises have discovered many innovative ways of brand communication, such as E-mail, SMS, virtual community, experience, word of mouth communication and clubs.

Through the above steps, the integrated strategy design of brand marketing concept communication is realized.

\subsection{The interactive strategy design of brand marketing concept communication}

The interactive strategy design of brand marketing concept communication is realized through two means of strengthening consumer experience and collecting consumer feedback.

The so-called experiential marketing is to redefine and design the thinking mode of marketing in the five aspects of consumers' Sense, Feel, Think, Act and Relate.

This way of thinking breaks the traditional assumption of "rational consumers" and holds that consumers are both rational and perceptual when they consume. The key to study consumer behavior and corporate brand promotion lies in consumers' experiences before, during and after consumption $^{[9]}$. In the increasingly fierce market, the single sales of products will soon be eliminated. Merchants need to stimulate consumers' sensory nerves and satisfy their inner latent unstimulated desire to extend and create the added value of products by experiencing. To do a good job in brand informazation, enterprises can start from the following three aspects: establishing information feedback system, broadening information feedback channels, and handling feedback information scientifically. Collecting feedback information from consumers and deeply exploring and analyzing the information is not only an effective method to accurately grasp the needs of target audiences. Enterprises can also accurately evaluate brand communication effect and timely adjust communication strategy based on the collected feedback from consumers, better inventory management and demand forecast to reduce inventory cost and resource waste, and conduct competitive research.

Through the above steps, the interactive strategy design of brand marketing concept communication is realized.

\subsection{Realization of the communication strategy design of local brand marketing idea under the new media environment}

In this paper, the design of local brand marketing concept communication strategy under the new media environment is divided into three parts: By creating a differentiated brand positioning and meeting differentiated audience needs, the differentiation strategy design of brand marketing concept communication can be realized. Through content integration, channel integration and mode integration, the integrated strategy design of brand marketing concept communication can be realized. The interactive strategy design of brand marketing concept communication is realized through two means of strengthening consumer experience and collecting consumer feedback. Complete the design of local brand marketing concept communication strategy under the new 
media environment.

\section{Experimental demonstration and analysis}

In order to ensure the effectiveness of the communication strategy of local brand marketing ideas in the new media environment designed in this paper, the effectiveness of this method is demonstrated and analyzed in the design experiment. During the experiment, the design method of this paper and the traditional communication strategy were respectively used to design the communication strategy of local brand marketing idea with the same type and the same scale of industry. Taking the marketing concept communication of two groups of local brands as the experimental object, as the process of generating effect through the dissemination of ideas requires a certain amount of time to accumulate, the experiment time is set as 6 months to obtain more clear experimental results. The new media communication effect and brand communication effect of the two communication strategies after 6 months were recorded and the experimental results were observed.

\subsection{Data preparation}

To ensure the accuracy of the experimental results, control the experimental variables. This paper tests the effectiveness of the communication strategy of local brand marketing idea under the designed new media environment. It is necessary to control other variables besides communication strategies, such as brand size and type of design, general cultural background and economic conditions of the region receiving marketing concept communication, so as to prevent the accuracy of the experimental results. In order to prove the effectiveness of the design strategy in this paper, the control group was selected after selecting the appropriate experimental object. To better determine the test results, the new media communication effect and brand communication effect evaluation system are set as shown in table $1^{[10]}$.

Table 1. New media communication effect and brand communication effect evaluation system

\begin{tabular}{|c|c|c|}
\hline Inspection project & Index & Explain \\
\hline \multirow{6}{*}{$\begin{array}{c}\text { New media } \\
\text { communication effect }\end{array}$} & Brand awareness & Audience's recognition of the brand \\
\hline & Brand attitude & $\begin{array}{l}\text { The audience expresses the overall judgment of the } \\
\text { brand according to the result of their own reasoning }\end{array}$ \\
\hline & $\begin{array}{l}\text { Brand } \\
\text { preference }\end{array}$ & Audience's preference for a certain brand \\
\hline & $\begin{array}{l}\text { Brand purchase } \\
\text { degree }\end{array}$ & $\begin{array}{c}\text { The percentage of consumers who consider and accept } \\
\text { brands to make purchases }\end{array}$ \\
\hline & Brand loyalty & $\begin{array}{l}\text { Consumers' intention and behavior of repeated purchase } \\
\text { of the brand }\end{array}$ \\
\hline & $\begin{array}{l}\text { Brand } \\
\text { attractiveness }\end{array}$ & $\begin{array}{c}\text { Brand inclusiveness, affinity, credibility, trial index, } \\
\text { conversion index, etc }\end{array}$ \\
\hline \multirow[t]{4}{*}{$\begin{array}{c}\text { Brand communication } \\
\text { effect }\end{array}$} & Exposure rate & $\begin{array}{l}\text { How much coverage is generated by the content and } \\
\text { information disseminated by new media }\end{array}$ \\
\hline & participation & $\begin{array}{l}\text { The measurement of participation can be quantitatively } \\
\text { assessed by specific parameters. }\end{array}$ \\
\hline & influence & $\begin{array}{l}\text { The assessment of the impact of communication needs } \\
\text { to be sustained in a long-term, systematic context }\end{array}$ \\
\hline & Line power & $\begin{array}{l}\text { Measure how communication can motivate the target } \\
\text { audience and translate its attention and influence into } \\
\text { the final purchase }\end{array}$ \\
\hline
\end{tabular}

\subsection{Comparison test results}

A comparative experiment was set up to disseminate the marketing concept of local brands in the new media environment with different communication strategies. After six months of continuous 
communication, the new media communication effect and brand communication effect brought by the two communication strategies were recorded. The test results of the new media communication effect of the two communication strategies are shown in figure 2.

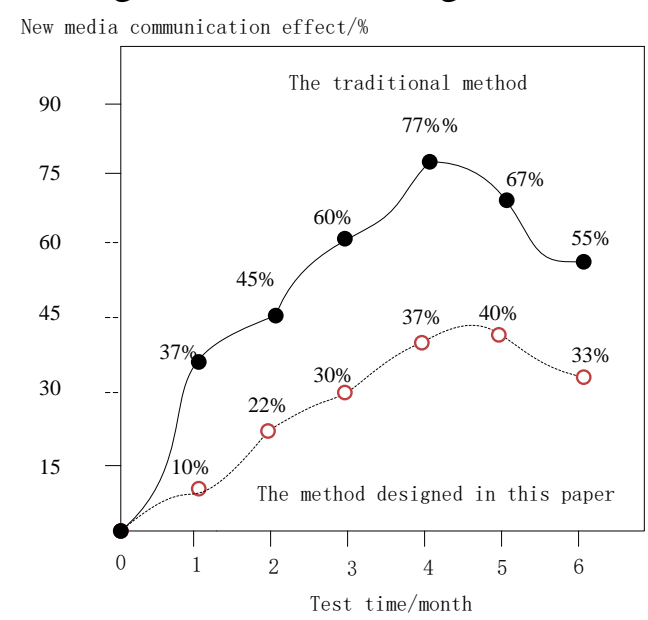

Figure 2. Comparison of new media communication effect test results between the two methods

As can be seen from figure 2, compared with the traditional method, the communication strategy of local brand marketing in the new media environment designed in this paper has obvious advantages in improving the communication effect of new media. In the process of comparative experiment, the change of the new media communication effect of the two methods was observed within six months. The communication strategy designed with the method in this paper has been significantly higher than the communication strategy designed with the traditional method. The communication strategy designed by using the design method in this paper achieved rapid results, with the highest new media communication effect reaching $77 \%$, and its average new media communication effect was $56.83 \%$. The effect of new media communication is slow, with the highest effect reaching $40 \%$ and the average effect of new media communication $28.67 \%$. Compared with traditional methods, this method can improve the communication effect of new media by $28.16 \%$.

The test results of brand communication effect of the two communication strategies are shown in figure 3.

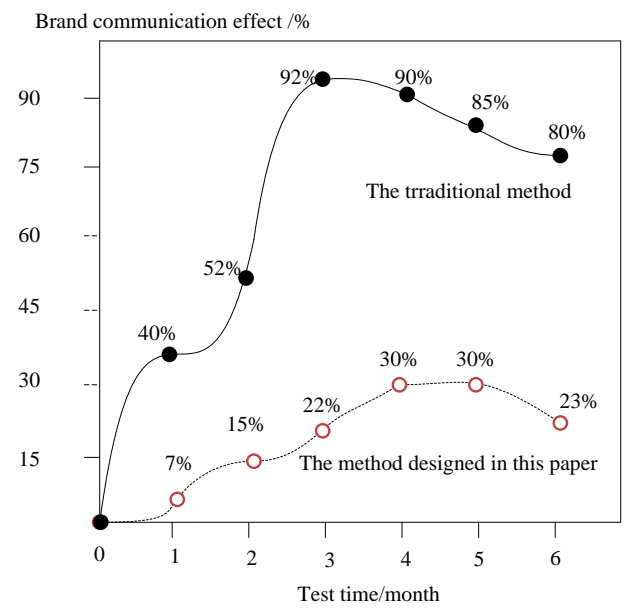

Figure 3. Comparison of brand communication effect Test results between the two methods

As can be seen from figure 3, compared with the traditional method, the communication strategy of local brand marketing concept in the new media environment designed in this paper has obvious advantages in improving brand communication effect. In the process of comparative experiment, the changes of brand communication effects of the two methods were observed within six months. The communication strategies designed with the method in this paper have been significantly higher than those designed with the traditional methods. The communication strategy designed by using 
the design method in this paper has a quick effect, with the highest brand communication effect reaching 92\%, and the average brand communication effect is $73.17 \%$. However, the communication strategy designed with traditional methods has a slow effect. The highest brand communication effect is only $30 \%$, and the average brand communication effect is $21.17 \%$. Compared with the traditional method, this method can improve the brand communication effect by $52 \%$.

To sum up, compared with traditional communication strategies, this design method can improve the effect of new media communication by $28.16 \%$ and brand communication by $52 \%$. It shows that the communication strategy of local brand marketing concept in the new media environment designed in this paper is highly effective.

\section{Conclusions}

The communication strategy of local brand marketing concept in the new media environment designed in this paper has been proved by experiments to be able to effectively improve the effect of new media communication and brand communication, and has high effectiveness.

\section{References}

[1] WANG Yanan, YU Min., (2017). Re-orientation of contents for popular science magazines under new media environment. Acta Editologica, 29(2):103-107.

[2] HOU Rui, YANG Li., (2017). Optimal Design Simulation of Brand Image under Visual Observation. Computer Simulation, 23(11):207-210.

[3] WANG Xiwei, XIANG Mengmeng, ZHANG Changliang, WANG Wei., (2017). Research on the Development Trend of Domestic and Foreign Information Privacy Under New Media Environment. Library and Information Service, 22(15):6-14.

[4] WANG Xiwei, XING Yunfei, WANG Nanaxue, LI Shimeng, (2017). An Empirical Study on Information Dissemination of Network Public Opinion on Emergencies under the New Media Environment. Information Studies:Theory \& Application, 40(9):1-7.

[5] CAO Yu, YU Zhengyu, WAN Guangyu., (2017). Evolutionary Game Study Between Government and Enterprises in Food Adulteration under the New Media Environment. Chinese Journal of Management Science, 25(6):179-187.

[6] XIE Min., (2017). EFFECTS OF AGRICURAL PRODUCTS OF GEOGRAPHICAL INDICATION ON BRAND MARKETING COMPETITIVENESS-TAKE SICHUAN PROVINCE FOR EXAMPLE. Chinese Journal of Agricultural Resources and Regional Planning, 38(4):207-213.

[7] WANG Zhan, FENG Fan., (2017). Brand Communication and Marketing Strategies Research under the Community Economy. Journal of Social Science of Hunan Normal University, 46(1):141-148.

[8] LI Pengju, CHAO Gangling, HUANG Pei., (2017). The New Dimensions of Store Image and Their Marketing Effects in the Era of Corporate Branding: An Improvement to the Attribute-based Measurement. Management Review , 29(1):187-198.

[9] SHI Congcong, HU Jueliang, HAN Shuguang., (2017). Competition and cooperation model construction and application in dual marketing channel for brand apparel. Journal of Textile Research, 32(5):157-162.

[10]ZHANG Yongtao., (2018). Research Progress and Enlightenment of Brand Image Transfer in Foreign Sports Sponsorship Marketing Activities. Journal of Chengdu Sport University, 34(2):212-215. 